\title{
Features of Lean Manufacturing in the Energy Sector
}

\author{
Badrieva R.R. ${ }^{1}$, Demyanova O.V. ${ }^{2}$, Andreychenko I.S. ${ }^{3}$ \\ ${ }_{1,2,3}$ Kazan Federal University, Kazan, Republic of Tatarstan, Russia, \\ ${ }^{2}$ Doctor of Economics, Professor, Head of the Department of Production Economics, Institute of Economics and Finance, Kazan \\ Federal University, http://www.scopus.com/authid/detail.url?authorId=55887163900, http://orcid.org/0000-0003-3438-1457,
}

\author{
${ }^{3}$ Student, Department of Production Economics, Institute of Economics and Finance, Kazan Federal \\ Universityhttps://orcid.org/0000-0002-9769-5704,
}

Corresponding author: ${ }^{1}$ Student, Department of Production Economics, Institute of Economics and Finance, Kazan Federal University, http://orcid.org/0000-0001-8710-0941

\begin{abstract}
One of the energy companies' main goal is the efficient use of energy. A mean of attaining this goal is the lean manufacturing concept, which is growing increasingly popular around the world. Lean manufacturing is a concept in production management focusing on continuous improvement and eliminating production wastes [1]. The philosophy behind lean manufacturing roots from the Toyota Productions System developed at the Japanese company Toyota. This paper reviews the specifics of lean manufacturing in the energy industry. It identifies key problems of the energy sector, provides global statistical data on energy losses and classifies them. Implementing "Lean Energy" would increase the competitiveness of the companies operating in the energy industry, reduce some of the energy losses, and, consequently, help reach a qualitatively new level of operations. Prospect results of implementing "Lean energy" at OAO "Setevaya kompaniya", a territorial energy company conducting energy transportation in the Republic of Tatarstan, are presented in this paper. The main stages in the development of "Lean Energy" at the company are reviewed. The lean tools and methods implemented at the company are presented, along with the results of an internal and external audits of the company's production system. The practical implications of the study are seen as provisions of results of the analysis presented in the paper for future use by the companies implementing the lean manufacturing management system.
\end{abstract}

Keywords: lean manufacturing, production system, Toyota Production System, methods, tools, Energy Company, lean audit

\section{INTRODUCTION}

Recently, the world has seen a number of new concepts and management methods being created, such as business process reengineering, Total Quality Management (TQM), balanced scorecard, statistical process management, ISO 9000, ISO 14000, HACCP, 5S, Six Sigma, and more.

One of the most relevant methods of production management is the Japanese concept of lean manufacturing (lean production), which implies continuous improvement of processes and elimination of all types of wastes present at the organisation. The philosophy of lean production was developed by an employee of the Japanese company Toyota (TPS - Toyota Production System) Taiichi Ohno in the postwar Japan, where the issue of restoring the country's industry and introducing its products to the global automotive markets became especially acute. [2] A huge contribution to the development of the lean manufacturing concept was made by Ohno's colleague Shigeo Shingo, who is also the inventor of the Single-Minute Exchange of Dies (SMED) system. [3] The novel Japanese concept of production involved the use of new organisational and technological solutions for assembly production and an individual approach to workers' motivation. A special system of mutual interest between the suppliers and the distributors of goods ascended Toyota onto a new level of operations in the late 1970s, facilitating effective development in the Japanese automotive market and ousting American manufacturers. The success of Toyota Production System marked a new stage in the global companies' understanding of this Japanese strategy, which subsequently led to the emergence of the lean management concept.

In post-industrial countries, lean systems have been widely developed and used for over a hundred years. A huge percentage of enterprises in Japan $(90 \%)$, as well as in the USA (60\%), Europe (50\%), Canada, and Australia have adopted lean manufacturing. The concept helps companies to harmoniously develop in all directions, providing an appropriate level of quality and services, while reducing costs and satisfying their employees with working conditions.

Despite the rich foreign and domestic experience in the lean manufacturing systems, researchers point out the objective 
organisational and methodological problems of introducing and adapting lean technologies to the specifics of some enterprises, especially those operating in the energy industry. The lean philosophy is being successfully applied in mechanical engineering, automotive industry (about $40 \%$ totally), that is, in those industries where the concept of lean production was first used at the very beginning of its formation and development by Henry Ford himself. Correspondingly, the majority of lean tools are aimed at solving the problems of flow mass productions. Over time, it has become possible to apply the concept of lean manufacturing at service enterprises, using the principles of the Kaizen philosophy. As for the energy and oil sectors, just $3 \%$ of the enterprises there implement lean technologies, and even them deal mostly with production and manufacturing.

Lean manufacturing is a complex process consisting of many tools. The following methods and tools of lean manufacturing are distinguished:

1. Work standardisation is an accurate description of each action performed and the rules for the implementation of production activities.

2. Organisation of workspace $(5 \mathrm{~S})$ is a technology for creating an effective workplace, consisting of 5 steps from sorting things on one's desk to continuous improvement.

3. Value Stream Mapping (VSM) is the display of information and material flows in the form of visual aids that can show their interrelationship.

4. Visualisation is a method to graphically present tools, details, rules, and other information so that every person can evaluate the state of the production system.

5. SMED system implies quicker equipment changeovers attained by converting internal changeover elements to external ones.

6. Inadvertent error prevention (Poka-Yoke) is the concept of mistake-proofing, having three main functions: warning, control, and halt.

7. Kanban is a system of information for regulating supply, production, and transportation of products so that they are delivered at the exact time and in the exact quantity.

8. Total productive maintenance (TPM) is a method for troubleshooting equipment throughout its entire life cycle. [4]

\section{LEAN MANUFACTURING IN THE ENERGY SECTOR}

The lean manufacturing programme in the energy sector or "Lean Energy" has its own characteristics due to the specifics of the industry and since the implementation of this concept will require its methods and tools to be adapted to the needs of the industry. The transition to lean production is an important stage in the development of the Russian energy industry. Unlike the improvements made by means of commissioning new capacities, which are largely influenced by the changing demand and the instability in financial markets, lean energy is built on a cost-free basis.

Today, Russian energy companies aim to provide a reliable, efficient, and safe source for the generation and transmission of energy. And this aspect of their activities is linked to the key problem these companies face, i.e. energy losses at the stages of transportation, transmission, and distribution of energy, as well as annually rising electricity rates. Scientists working in this field also mention significant excesses in the capacities of the Soviet-era power plants in comparison with the European ones as another problem inherent to the industry. This is explained by the need to ensure the continuous operation of the energy-generating equipment in the case of emergency; high yearly fluctuations in energy consumption in Russia due to the country's climate; excessive regulations imposed on companies by the authorities, etc.

Then what is thought to be the main problem of the Russian energy companies? The loss of electricity represents the difference between the energy supplied to consumers and that received by them. There is a classification of electricity losses created for their standardisation and further calculation of the actual volume of losses:

1. Technological factors, depending on:

- the nature of physical processes caused by fluctuations in station loads, for example, losses on power grids;

- fixed costs, for example, idle work of power plant units;

- climatic conditions, for example, the freezing of electric power transmission wires.

2. The costs associated with the operations on auxiliary equipment and the provision of vital working conditions for technical staff, for example, ventilation, heating, etc.

3. A commercial component characterised by underaccounting of electricity, for example, errors of metering devices, theft of electricity, etc. 


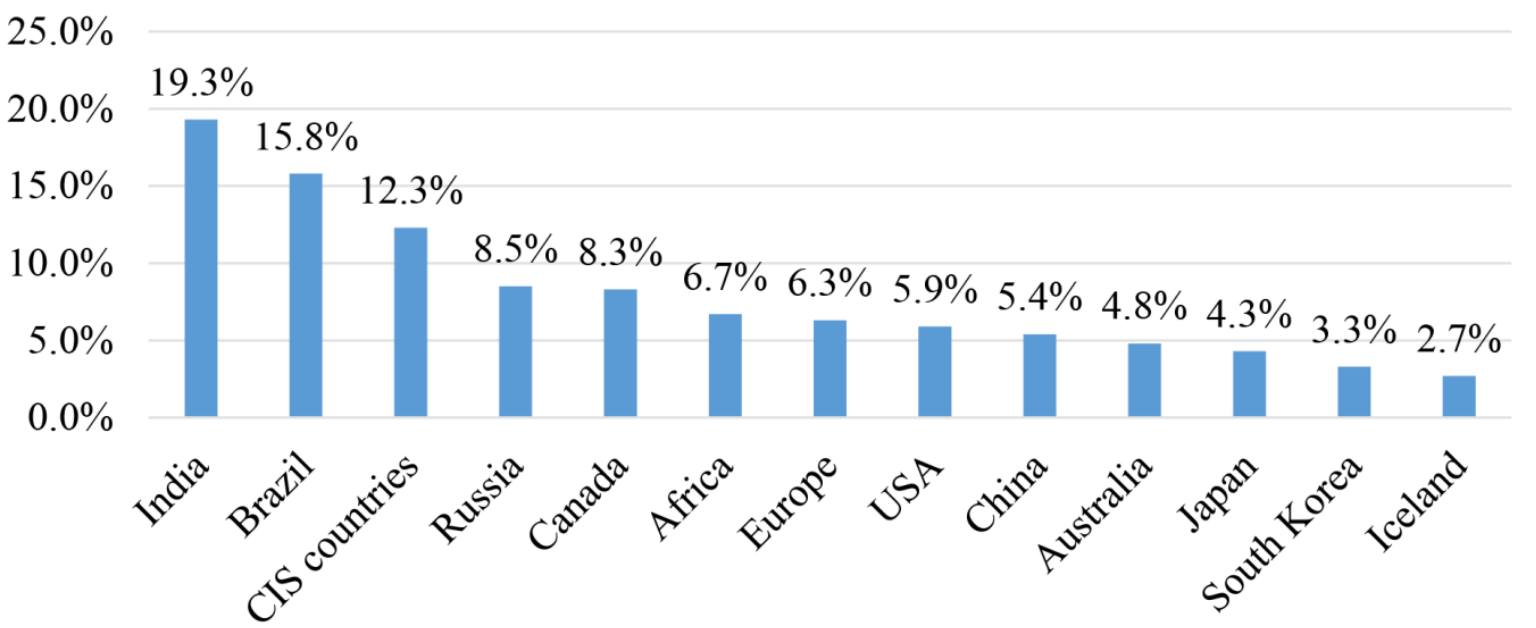

Figure 1. World Statistics of Electricity Losses in the Grid Complex for 2019, \% [5]

Based on the international statistics on the energy sector (Figure 1), we may conclude that, in advanced economies, the level of energy losses varies from $5 \%$ to $6 \%$, while in developing countries the figure reaches $10-30 \%$. In 2019 , the list of the most economical countries was headed by Iceland and South Korea, where electricity losses amounted to $2,7 \%$ and $3,3 \%$, respectively. The worst indicator was shown in India, where the level of energy loss in networks amounted to $19 \%$ (since the 2000 s, the indicator has decreased by $11 \%$ ).

Today, Russia has an average level of electricity losses. According to the 2019 data, the Russian Federation lost $8,46 \%$ of electricity during transmission over power grids. Over the past few years, Russian statistics have taken a momentum to improve, and since 2013, PAO "Rosetti" has reduced electricity losses to $8,8 \%$, with plans on further reduction to $6-8 \%$ by 2021 .

The philosophy of lean manufacturing distinguishes the following basic principles:

\section{- determining the value of a product;}

- value stream mapping a product;

- ensuring a continuous flow of value creation;

- devising a system of pulling the product's value from the consumer; establishing a continuous improvement process. [6]

When examining the specifics of lean energy, it should be noted that there are significant differences in the interpretations of the above-mentioned principles, that were initially developed for the assembly line production.

1. In the energy industry, the term "product" may either denote a specific service, for example, energy production, its transportation or distribution through power grids, etc., or can directly refer to the product itself, for example, heat or electricity. In an attempt to understand the essence of the energy sector's product, the social responsibility of the industry should be taken into account, expressed in the cross-subsidisation between the activities and consumer groups. This leads to the duality of product as a concept. It should also be borne in mind that, while electricity and heat are generated in a single cycle, the flows of creating their value are different.

2. Pull-production. On the one hand, pulling occurs naturally due to the physical nature of the product. While on the other hand, energy consumers do not have the opportunity to directly participate in assessing and defining the product's value. This is primarily due to the fact that energy companies tend to be monopolistic, and, subsequently, energy consumers do not have the opportunity to choose their supplier. The second reason for this phenomenon is the insufficient development of the heat and electricity metering system. As such, based on the above-mentioned factors, we can conclude that it is the energy companies themselves that manage the demand for their product, which allows them to save up on capital and operating costs.

3. The next difference is energy companies' motivation for continuous improvement. Leading companies that have achieved significant results thanks to the implementation of lean production. In particular, the Japanese company Toyota uses the economies of scale to drive down fixed and variable costs. This, however, is irrelevant for the domestic energy companies, primarily because the end consumers of electricity here are mainly individuals and not ogranisations. The second reason is the negative demography situation in the country, as well as the absence of a low number of energy-consuming companies with a rapidly growing power load. Due to the specifics of lean manufacturing in the energy sector, the issue of the lean tools effectiveness becomes even more important. Therefore, in addition to corporate methods, government support is required to modernise the energy market by facilitating competition in the retail and wholesale markets, and also to reform the regulatory system in order to optimise production processes.

By introducing lean production tools into organisational and production processes, the energy industry operators can achieve the following results: 
- Streamline the organisation of workplaces for storing information, material and technical resources;

Optimise their activities by conducting researches and modelling the production and managerial business processes;

- Introduce new production facilities and adopt innovative technologies;

Reduce the level of electricity losses during transmission over power grids;

- Use a quicker changeover system and create flexible jobs;

- Optimise the time resources of employees;

- Standardise and visualise production and office processes.

Today, the concept of lean energy is being actively introduced into the energy conservation programme. For example, the strategic task of being energy efficient implies reductions in energy consumption for the company's own needs, both economic and technological. In order to reduce wastes from the technological needs, an expensive replacement of equipment is required. But the company can reduce energy consumption from its economic needs, which does not require large investments. And here it becomes necessary to change the work attitude of staff and teach them how to save energy.
Thus, using the concept of lean energy, many global companies have achieved significant results and millions in cost savings. The Russian electric power industry has enormous potential and can save billions if lean manufacturing tools are applied effectively. Energy consumers will benefit the most from the introduction of the lean system, since it would increase reliability, supply quality and reduce the electricity rate burden by minimising the need for capital investments.

\section{OAO "Setevaya Kompaniya" Lean Manufacturing System Analysis}

Let us review the features of the lean manufacturing organisation in the energy industry as exemplified in the case of OAO "Setevaya kompaniya", which is a territorial network organisation that provides services for the transmission of electricity and technological connection of consumers to the organisation's electric grids in the Republic of Tatarstan.

One of the company's strategic goal is to continuously improve business processes and increase the efficiency of production. The introduction of lean manufacturing at $\mathrm{OAO}$ "Setevaya kompaniya" began in 2014 with the "Energiya" production system.

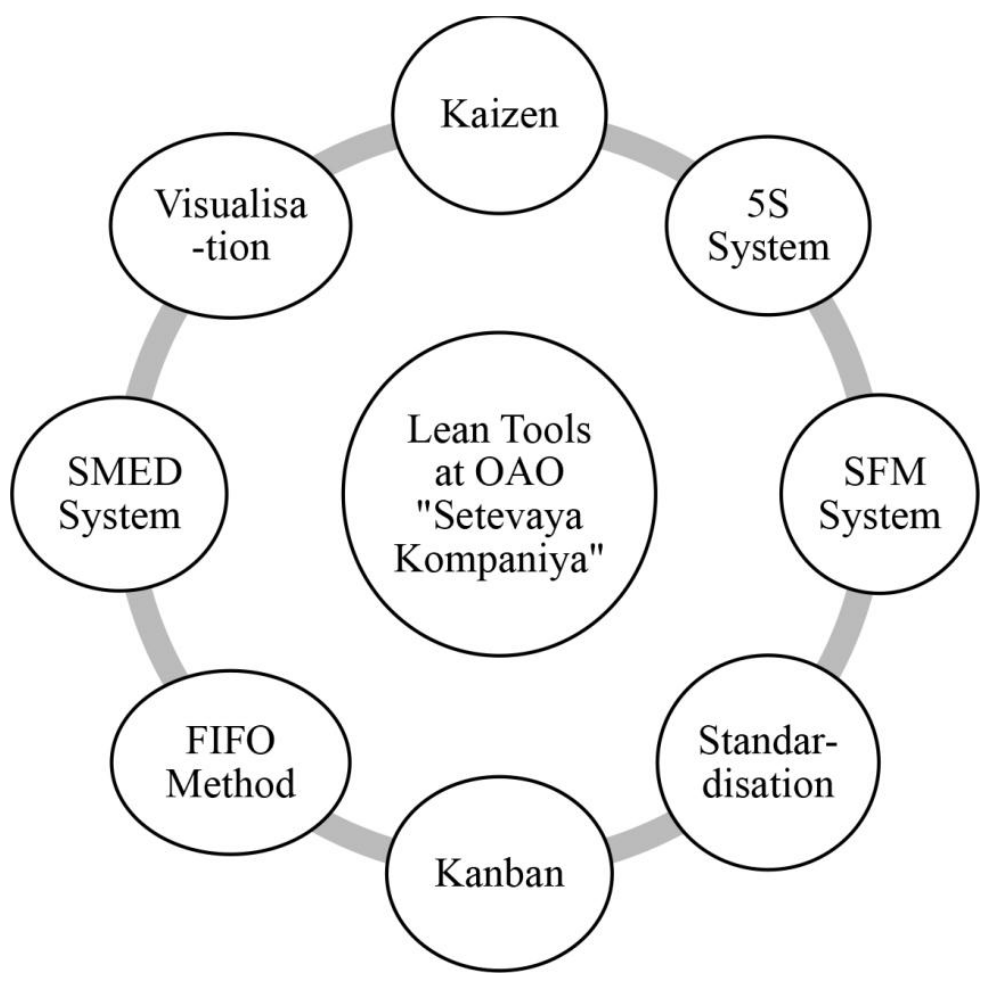

Figure 2. Lean Manufacturing Tools and Methods Implemented at OAO "Setevaya Kompaniya" [7]

Currently, 8 lean manufacturing tools have been implemented at the company (Figure 2).

The number of Kaizen proposals submitted is growing annually. In 2019, the number of proposals for continuous improvement reached 22,749. Due to the specifics of the company the majority of proposals were submitted by technical staff. By implementing lean manufacturing, OAO "Setevaya kompaniya" seeks to increase employees' interest in improving the organisation's activities and because of this 
the company provides material incentives for submitting Kaizen proposals. In 2019, the level of employees' involvement into the implementation of the "Energiya" production system amounted to $92,1 \%$.
As a part of the lean manufacturing programme, an audit of the $5 \mathrm{~S}$ system is conducted annually at OAO "Setevaya kompaniya". The results of the 2019 audit with division by branches are presented in Figure 3

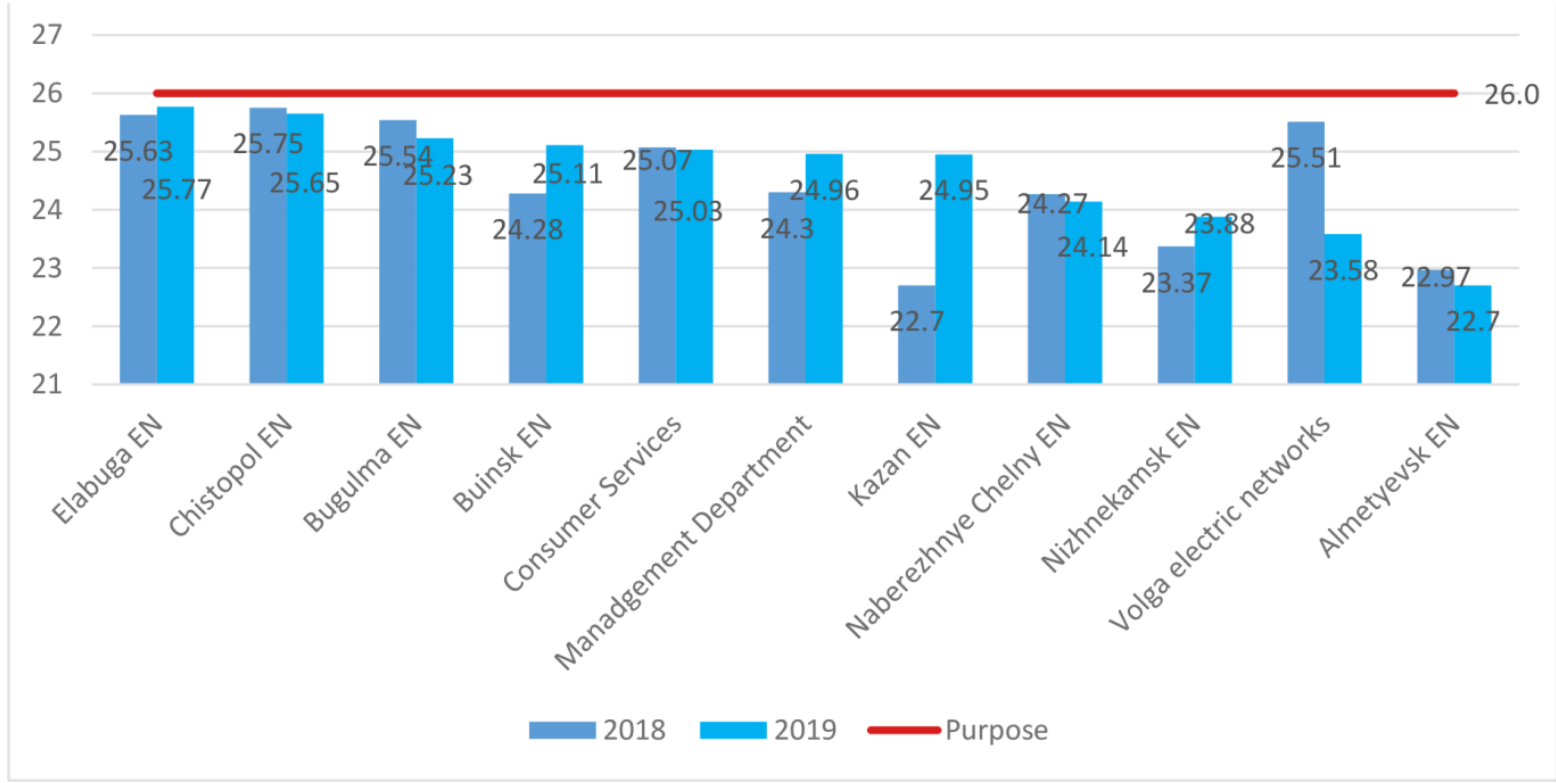

Figure 3. The Results of the 5S System Audit for the Branches of OAO "Setevaya Kompaniya", 2019 [8]

During a random audit on the $5 \mathrm{~S}$ system, the following findings were identified:

1. There is no sorting of tools and materials in production facilities, nor the objects and documents at the office units.

2. Systematic cleaning of the territory and premises is not controlled and is not carried out.

3. No visualisation of folders, shelves, cabinets, trays at the office units.

4. No visualisation in the production rooms of structural units (namely, warehouses, workshops, boxes)

5. The existing visualisation contradicts with actual objects.

6. The standard number does not comply with the list of basic standards approved by the company.

7. Lack of workplace standards reflecting the essential characteristics of the work area.

The weaknesses identified during the $5 \mathrm{~S}$ system audit prove the importance of internal audits in the development of lean manufacturing in the organisation. The findings are to be studied and measures are to be taken by the employees with a photographic report on the work done. An intermediate monitoring system would eliminate bottlenecks and improve staff performance in the company.

In 2018, an external audit of the "Energiya" production system was conducted by Toyota Engineering Corporation. [9]. During the visit, TEC auditors held a meeting with the executives responsible for the development of lean manufacturing at the company. After the meeting, the auditors began the production and office premises inspection of the company's branches.

The results the "Energiya" production system audit as to the Toyota Production System are presented in Table 1. [8] The rating for each criterion was set on a five-point scale, with 1 ranking the worst result, and 5 ranking the best. According to the results of the TPS audit, the "Energiya" production system was rated at 2,47 points, showing a two-fold increase compared to the 2014 rating, which amounted to 1,23 points. Within the framework of lean production, the company's further goal is to attain TPS Bronze Level (3 points). This time, the "Energiya" production system was assessed in six areas: activisation of the work environment (its attractiveness), management involvement (management and its visualisation), staff (employees' actions), raw materials and supplies (logistics), equipment (degree of work efficiency), quality (coverage by production staff). [10] 
International Journal of Engineering Research and Technology. ISSN 0974-3154, Volume 13, Number 11 (2020), pp. $3530-3536$

(C) International Research Publication House. https://dx.doi.org/10.37624/IJERT/13.11.2020.3530-3536

Table 1. T-TPS Criteria Audit Results, 2018

\begin{tabular}{|cc|c|c|c|}
\hline \multicolumn{2}{|c|}{ Criteria For Assessment } & Audit No1, 12.2012 & Audit No2, 08.2018 & TPS, 08.2018 \\
\hline 1. & Revitalisation & 1,5 & 2,68 & 2,37 \\
\hline 2. & Management & 1,0 & 2,78 & 2,45 \\
\hline 3. & Staff & 1,6 & 2,82 & 2,44 \\
\hline 4. & Materials & 1,1 & 2,72 & 2,35 \\
\hline 5. & Equipment & 1,2 & 3,56 & 2,47 \\
\hline 6. & Quality & 1,0 & 2,88 & 2,46 \\
\hline \multicolumn{2}{r|}{ Final score: } & 1,23 & 2,91 & \\
\hline
\end{tabular}

During the "Energiya" production system audit conducted by Toyota Engineering Corporation, Toshio Horikiri, the president TEC, noted that OAO "Setevaya kompaniya" had achieved a high level of process control and organisation of the $5 \mathrm{~S}$ system in the workplaces of employees. Some remarkable and high-quality Kaizen proposals were also noted in each division of the company. An objective assessment was given during the audit, bottlenecks were identified and recommendations for improving "Energiya" production system were proposed.

The President of the Japanese company stressed the OAO "Setevaya kompaniya's" enormous potential for development and also gave a number of recommendations on improving the "Energiya" production system:

- activation of quality groups;

- expanding the goals to linear level;

- preventive management through operational monitoring of trends;

- standardisation of visual quality control tools;
- development of a vocational training system with regard to personal career plans;

- organisation of a system of the production process integrated quality control;

- improving the relationships between units;

- increasing staff competencies in the field of lean manufacturing;

- visualisation of the maximum/minimum level of inventory control;

- organisation of a replenishment system functioning as a supermarket;

- systematic assessments.

When implementing the tasks recommended by the Japanese expert, such as optimising the coordination and deployment of a corporate course, setting goals in numerical terms, further developing the company's production system, activating personnel in the workplace, and developing human potential, OAO "Setevaya Kompaniya" will speed up the process of attaining TPS Bronze Level.

Table 2. "Energiya" Production System Implementation Main Results, 2017-2019

\begin{tabular}{|c|c|c|c|}
\hline Indicators & 2017 & 2018 & 2019 \\
\hline $\begin{array}{l}\text { Training on Lean Principles and Methods Delivered to New Staff } \\
\text { Members, ppl. }\end{array}$ & 533 & 616 & 501 \\
\hline Staff Trained, ppl. & 849 & 3216 & 6448 \\
\hline Projects Accepted & 116 & 91 & 78 \\
\hline Projects Implemented & 47 & 90 & 71 \\
\hline Kaizen Proposals Submitted & 15233 & 22533 & 20145 \\
\hline Kaizen Proposals Implemented & 14744 & 21892 & 19459 \\
\hline Freed-Up Space, sq. m. & 4783 & 3839,7 & - \\
\hline Economic Impact, millions of roubles & 97,7 & 199,8 & 81,3 \\
\hline Life Extension Costs (Staff Motivation Included), millions of roubles & 70,8 & 82,9 & 83,7 \\
\hline Life Extension Costs as \% of the Actual Economic Impact & 42 & 29,3 & 50,7 \\
\hline
\end{tabular}


The lean manufacturing concept is one of the most productive tools for achieving productivity goals. The results of the implementation and development of the lean energy programme at OAO "Setevaya kompaniya" were:

1. 5740,8 man-hours increase in labor productivity;

2. 3839,7 sq. m. of freed-up space;

3. $92,1 \%$ level of employee involvement in the company affairs;

4. A T-TPS rating of 2,91 based on the assessment of the effectiveness of the "Energiya" production system (a rating of 3 required for TPS Bronze Level);

5. The economic impact amounted to 199.8 million roubles. [8].

To eliminate all types of wastes at OAO "Setevaya kompaniya", measures should be taken for further development at lean management. Also, the company should use a combination of lean manufacturing and Industry 4.0 concepts for its future development, in order to ensure reliable, high-quality, and affordable power supply for the consumers connected to the company's network, to create conditions for the efficient operations of enterprises and organisations, comfortable and safe life of the population to facilitate the dynamic socio-economic development of the Republic of Tatarstan [11]. For example, wearing virtual reality goggles will allow managers to stay present in gemba, i.e. right where value is created, as to control production processes and plunge into the working atmosphere.

\section{SUMMARY}

Based on the study of the lean manufacturing programme implementation in the energy sector (known as "Lean Energy"), we can conclude that it has its own special characteristics, which root from the specifics of the industry. The implementation of this concept will require the adaptation of its methods and tools for the industry's requirements. "Lean energy" is a promising step in the development of the domestic energy industry and is capable of yielding significant results.

\section{CONCLUSIONS}

The study of the "Energiya" production system at OAO "Setevaya kompaniya" speaks of the company's sustainable and continuous development. The number of Kaizen proposals submitted and the involvement of employees in the development of lean energy increase annually. Periodical internal audits of tools and methods of the lean system are being conducted, and the checklists used in the company are clearly regulated and developed. This is indicative of an ongoing systematic monitoring of the organisation's production programme. An important stage in the development of lean production was the company's external TPS system audit, conducted by the Toyota Engineering Corporation CEO Toshio Horikiri. In the course of this audit, the company determined its wastes within the framework of lean production and their causes, and received recommendations on the production system improvements.
Measures should be taken to eliminate the identified problems, further develop the lean management methods and bring the company to TPS Bronze Level. Also, in order to ensure a reliable, high-quality, and affordable power supply to consumers connected to the electric network, the company should conduct its development in a symbiosis of two concepts - the lean manufacturing and Industry 4.0 concepts. This will ensure that OAO "Setevaya kompaniya" achieves its strategic goals, such as reaching maximum efficiency and reliability of existing assets, introducing new effective technologies and equipment, creating the opportunities for each client's technological connection, increasing the investment attractiveness and capitalisation of the company in the best interests of shareholders, increasing efficiency and corporate governance qualities.

\section{ACKNOWLEDGEMENTS}

The work is performed according to the Russian Government Program of Competitive Growth of Kazan Federal University.

\section{REFERENCES}

[1] Womack JP, Jones DT. Lean thinking - banish waste and create wealth in your corporation. Journal of the Operational Research Society. 1997 Nov $1 ; 48(11): 1148$

[2] Ohno T. Toyota production system: moving away from mass production. M.: Publishing house of the ICSI. 2012.

[3] Shingo S. The Study of Toyota production system. From an Industrial Engineering Viepoint. Moscow. Institute for Integrated Strategic Studies. 2006:88-289.

[4] Tyagi S, Cai X, Yang K, Chambers T. Lean tools and methods to support efficient knowledge creation. International Journal of Information Management. 2015 Apr 1;35(2):204-14.

[5] Economic and financial data EconomicData.ru. [Electronic resource] Available at: https://www.economicdata.ru/index.php

[6] J. Liker, "The Toyota Way: 14 Management Principles from the World's Greatest Manufacturer," Moscow: Alpina Business Books, 68 p. 2005.

[7] The annual report of the grid company, 2019. [Electronic resource] Available at: http://gridcom-rt.ru/

[8] Report on the development of the production system "Energy", 2019. [Electronic resource] Available at: http://gridcom-rt.ru/

[9] Toshio Horikiri. TPS and TMS - Systems for Company Development. Toyota Engineering Corporation, 2014.

[10] Tosio Khorikiri. Experience in implementing the Japanese Production Management System (TPS) in Russia. Seminar Toyota Engineering Corporation, Novosibirsk. 2012:1-26.

[11] World Economic Forum and McKinsey \& Company, Fourth Industrial Revolution: Beacons of Technology and Innovation in Manufacturing. World Economic Forum: Geneva, Switzerland, 2019. 